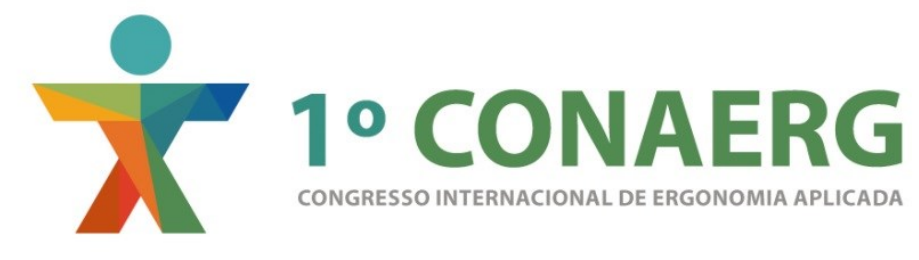

\title{
Ergonomia Cognitiva no Ambiente Universitário: Análise da orientação espacial dos estudantes de arquitetura na Universidade Federal de Juiz de Fora (UFJF)
}

\author{
José Alberto Barroso Castañon (1); \\ Carla Bernardes de Rezende (2); \\ Jéssica de Fátima Rossone Alves (3); \\ Juliana Varejão Giese (4); \\ Sayhane Rodrigues de Paiva (5).
}

(1) Universidade Federal do Rio de Janeiro, Doutor em Engenharia de Transportes.

e-mail: jose.castanon@ufif.edu.br

(2) Universidade Federal de Juiz de Fora, Arquiteta e Urbanista.

e-mail: carlabrezende@yahoo.com.br

(3) Universidade Federal de Juiz de Fora, Arquiteta e Urbanista.

e-mail: jessica rossone@hotmail.com

(4) Pontifícia Universidade Católica do Rio de Janeiro, Arquiteta e Urbanista.

e-mail: varejaoj@gmail.com

(5) Universidade Federal de Juiz de Fora, Designer de Produto.

e-mail: sayhanerodrigues@gmail.com

\section{RESUMO}

Esta pesquisa tem como objeto de estudo o ambiente construído da Faculdade de Engenharia da Universidade Federal de Juiz de Fora - MG. Como principal objetivo tem-se a análise da orientação e percepção dos alunos do primeiro período do curso de Arquitetura e Urbanismo da instituição com o espaço em questão, até então desconhecido pela maioria deles. Após realizada a revisão bibliográfica sobre o tema, foram aplicados questionários na turma. Apresenta-se como resultado as principais dificuldades e facilidades de orientação indicadas pelos alunos, bem como os motivos pelos quais indicam ser fácil ou difícil se orientar no espaço estudado. 


\section{ABSTRACT}

This research has as object of study the built environment of the Faculty of Engineering, Federal University of Juiz de Fora - MG. Main objective is the analysis of orientation and perception of students in the first period of the course of Architecture and Urbanism with the space in question, unknown to most of them even now. After reviewing the literature on the topic, questionnaires were applied. As results, this study presents the main difficulties and facilities indicated by the students as well as the reasons which indicate that it is easy or difficult to orient the study space.

\section{INTRODUÇÃO}

Diversos estudos têm revelado que é cada vez maior o interesse sobre percepção do usuário no ambiente construído. Segundo Bins Ely (2013), a percepção oferece informações necessárias para o indivíduo entender e se orientar em um determinado ambiente. Cada indivíduo pode reagir de maneira diferente diante do ambiente em que vive e as manifestações recorrentes dessa reação resultam na percepção, processos cognitivos, julgamentos e expectativas de cada um (FERNANDES, SOUSA, PELISSARI et al., 2005). Assim, os estudos voltados para percepção do homem no ambiente se tornam importantes para compreender o comportamento do usuário no espaço e o que ele espera do mesmo.

Embora os estudos sobre percepção e orientação do homem no ambiente construído sejam crescentes, observa-se que ainda existem poucos estudos que abordam com ênfase essa relação em espaços universitários. Dessa forma, o artigo apresenta um trabalho de pesquisa sobre ergonomia cognitiva no ambiente construído aplicada à Faculdade de Engenharia (FE) pertencente à Universidade Federal de Juiz de Fora - MG (UFJF). A partir da observação da interação entre os estudantes e as características arquitetônicas do conjunto predial que compõe a Faculdade de Engenharia, manifestou-se a pertinência em analisar pontualmente o modo como os alunos se orientam e percebem o ambiente no qual estão presentes cotidianamente.

O desenvolvimento deste artigo está dividido em seis itens que discorrem acerca da ergonomia cognitiva do ambiente universitário em questão e dos procedimentos para a análise da orientação e percepção espacial dos estudantes que são a fonte de dados para a pesquisa. O item 2, "Ergonomia cognitiva no ambiente construído: percepção espacial e orientabilidade", esclarece os principais conceitos fundamentais à temática. No item seguinte, é relatado o processo de configuração do conjunto da Faculdade de Engenharia, desde a fundação da Universidade Federal de Juiz de Fora até o presente. Já o item 4 explicita a definição do grupo de alunos definidos para se realizar a pesquisa, assim como a metodologia utilizada para se obter os resultados. A análise dos dados e as considerações finais são apresentados nos itens 5 e 6 , respectivamente.

A pesquisa expõe, portanto, a percepção e a qualidade de orientação dos alunos no conjunto que compreende a Faculdade de Engenharia. Por fim, 0 artigo aponta indiretamente as deficiências e qualidades arquitetônicas e ergonômicas que influenciam na orientação espacial dos estudantes nesse ambiente.

\section{ERGONOMIA COGNITIVA NO AMBIENTE CONSTRUÍDO: PERCEPÇÃO ESPACIAL E ORIENTABILIDADE}

O termo ergonomia foi utilizado pela primeira vez pelo inglês Murrel e adotado oficialmente em 1949, ano da criação da Ergonomics Research Society (LAVILLE, 1977), sociedade esta que reunia psicólogos, fisiologistas e engenheiros com especial interesse na área. 
Segundo a Associação Brasileira de Ergonomia, dentro do âmbito de especialização da ergonomia está a ergonomia cognitiva que "se refere aos processos mentais tais como percepção, memória, raciocínio e resposta motora conforme afetem as interações entre seres humanos e outros elementos de um determinado sistema" (ABERGO, 2016). Podem ser citados como objetos de estudo da ergonomia cognitiva a tomada de decisão, 0 estresse, o treinamento e a carga mental envolvidos em determinada atividade.

A ergonomia cognitiva no ambiente construído trata das questões resultantes das interações entre homem, espaço e atividade a ser realizada. Logo, admite-se que o desenvolvimento da atividade depende de fatores de domínio cognitivo que envolvem conhecimento, compreensão e avaliação, e domínio psicomotor, tais como a percepção espacial, posicionamento e mecanização das atividades. (ABBAD, BORGES-ANDRADE, 2004). Neste sentido, o desenvolvimento da atividade dependerá diretamente da compreensão do ambiente construído por parte do indivíduo bem como da sua percepção do espaço no qual a atividade acontece, ou seja, da orientabilidade do ambiente.

A orientabilidade é definida como "a facilidade ou não de orientar-se no espaço através da interpretação do ambiente" (RIBEIRO, MONT'ALVÃO, 2004) e é responsável por fornecer aos usuários as informações adequadas de onde ele está e como encontrar o local desejado, através de uma sequência de ações que forneçam a melhor rota para se chegar ao destino, assim como estabelecer o retorno ao local de origem. Dentro da psicologia cognitiva, a orientação espacial é a capacidade em formar mapas mentais. Para tanto, se um indivíduo consegue elaborar um mapa mental adequado do ambiente e se situar nele, ele "consegue se orientar de forma precisa e correta, pois o mapa é a fonte de informação para a tomada de decisão". (BINS ELY; DISCHINGER; MATTOS, 2002).

O processo de orientação espacial, também chamado de wayfinding, compreende uma sequência de ações e começa por "saber onde se está, para onde se quer ir, como chegar lá através da escolha da melhor rota para esse destino, reconhecer o local de destino no momento em que chegar nele e conseguir inverter todo o processo, isto é, encontrar o caminho de volta" (CARPMAN, s/d).

É importante compreender a influência do ambiente construído no comportamento do usuário e os constrangimentos sofridos por ele e, no caso de indivíduos envolvidos em uma atividade cotidiana, esta necessidade acentua-se. É nesse propósito que se desenvolve este estudo, a partir da análise da percepção espacial e orientabilidade dos indivíduos questionados.

\section{O AMBIENTE CONSTRUÍDO DA FACULDADE DE ENGENHARIA DA UNIVERSIDADE FEDERAL DE JUIZ DE FORA}

A Universidade Federal de Juiz de Fora teve seu primeiro projeto elaborado pelo engenheiro e arquiteto Artur Arcuri (1913-2010), em meados da década de 1960. Entre as suas primeiras construções estão aquelas que receberam a Escola de Engenharia, delimitadas em um único platô, numa das áreas de maior altitude do campus (Figura 01). Dentro da Faculdade de Engenharia funcionam, atualmente, doze cursos de graduação, incluindo Arquitetura e Urbanismo, três cursos de pós-graduação e três programas de mestrado, como o Mestrado em Ambiente Construído, e os Doutorados em Engenharia Elétrica e Modelagem Computacional (Faculdade de Engenharia/UFJF, s/d).

O acesso à Universidade é feito através de dois pórticos, geograficamente opostos, que conectam a Universidade à cidade, adicionando a ela, inclusive, a característica de ligação entre bairros. A partir da via principal, em mão única, os acessos se ramificam em vias sem saída. A Faculdade de Engenharia recebe o fluxo de automóveis, ônibus urbanos e ônibus circular da UFJF através da única e mesma via secundária. Os acessos a pé são feitos pela mesma via ou através de uma escada que conecta o platô da FE diretamente ao Pórtico Norte. 
Figura 01: Mapa de localização da Faculdade de Engenharia dentro do campus da UFJF.

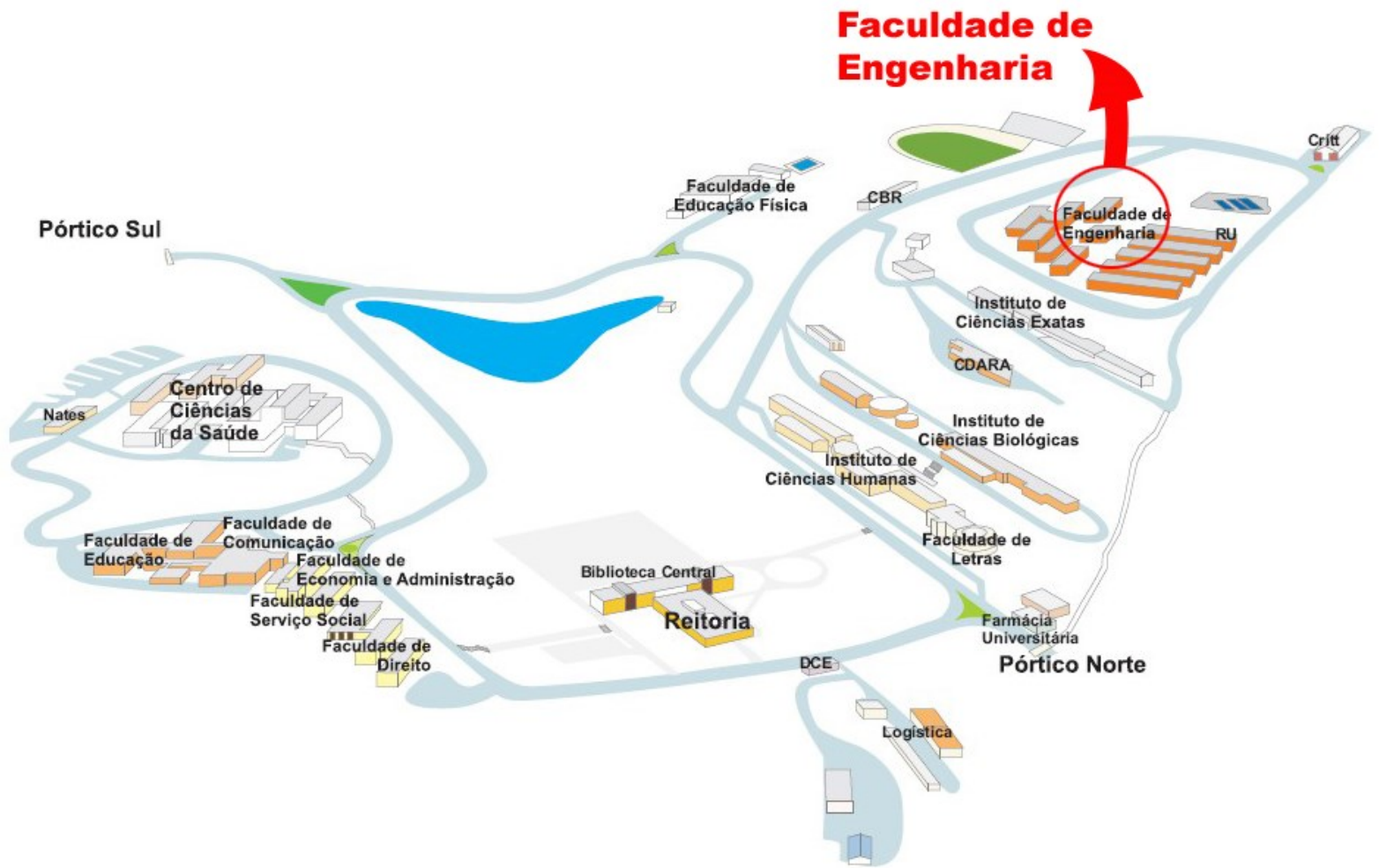

Fonte: Website da Faculdade de Engenharia-UFJF. Disponível em:

<http://www.ufjf.br/engenharia/files/2009/01/mapa_fac_engenharia.jpg> Acesso em: 27 junho 2016.

O platô da Faculdade de Engenharia, atualmente, integra sete edificações voltadas especificamente para o ensino dos cursos de Engenharia e de Arquitetura e Urbanismo: 4 galpões, 1 edificação em 6 blocos e 1 edificação que contempla o anfiteatro e a cantina datadas, conforme informações da SECOM (Secretaria de Comunicação da UFJF), do período da fundação da Universidade (1960) - e o Edifício Engenheiro Itamar Franco, construído em 2011 (Figuras 02 e 03).

Figura 02: Faculdade de Engenharia / UFJF, um dos edifícios datados do período da fundação da Universidade (1960) à esquerda e Edifício Engenheiro Itamar Franco (2011) à direita.

Fonte: Arquivo próprio, 2016
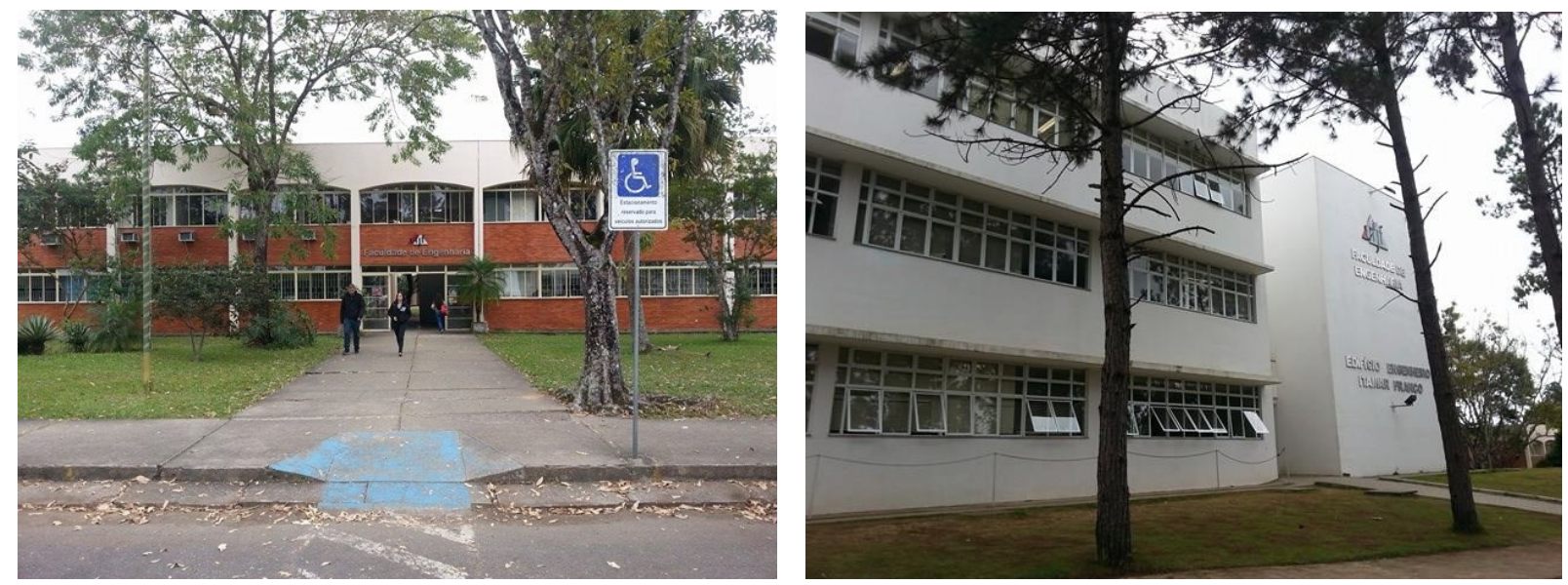

Nos últimos dez anos, em resposta à demanda de espaços para novos cursos da instituição e, portanto, maior número de alunos, houve uma produção acelerada de novas edificações, como o Edifício Engenheiro Itamar Franco (2011), o edifício do Instituto de Artes e Design (2010), bem como a ampliação do Restaurante Universitário (2009) e a construção 
da nova Biblioteca (2014) (SECOM, 2009; Instituto de Artes e Design/ UFJF, s/d). Essas transformações afetam diretamente a percepção e orientação dos usuários desses espaços, devido à mudança na paisagem ao redor, e o funcionamento do ambiente ao incentivar o fluxo por intermédio de seus prédios e a utilização de suas áreas comuns (Figura 03).

A exemplo disso, o curso de Arquitetura e Urbanismo, criado em 1992, foi disposto nos edifícios da Faculdade de Engenharia (FE), juntamente com os cursos de graduação e pós-graduação em Engenharia. Inicialmente instalado no Galpão 4 da FE, o ambiente utilizado pelo curso foi expandido para o Bloco A do Campus em 2008, de forma a atender exigências feitas pelo MEC. Em 2014, o curso foi desvinculado da Faculdade de Engenharia e foi fundada a Faculdade de Arquitetura e Urbanismo (FAU). Esta, porém, ainda utiliza toda a infraestrutura da FE: salas de aula, copiadora, cantina, anfiteatro, biblioteca, dentre outros, tendo como instalações exclusivas o Galpão 4 (Galpão da Arquitetura) que, atualmente, acomoda salas de núcleo de pesquisa, laboratórios, ateliês de projeto, salas de aula de desenho, salas de aula de maquete, salas dos professores, coordenação do curso e secretaria da FAU. Algumas disciplinas passaram a ser ministradas no terceiro pavimento do Edifício Engenheiro Itamar Franco desde a sua inauguração, em 2011, enquanto que seus demais pavimentos são destinados às aulas dos cursos de Engenharia (UFJF, 2016).

Figura 03: Mapa da Faculdade de Engenharia - UFJF.

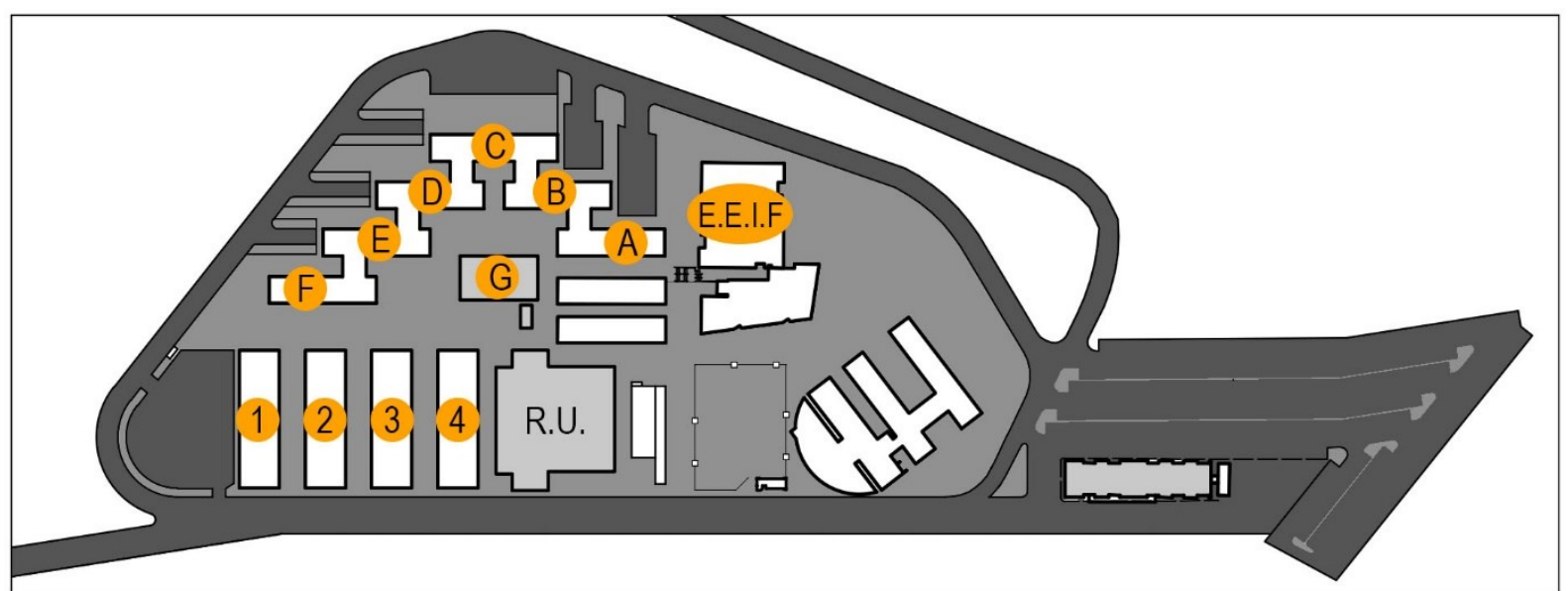

$1,2,3$ e 4 - Galpões

A,B,C,D,E e F - Blocos Faculdade de Engenharia

G - Bloco Cantina e Anfiteatro

Fonte: Elaborado pelos autores
E.E.I.F. - Edifício Engenheiro Itamar Franco R.U. - Restaurante Universitário

\section{GRUPO DE AMOSTRAGEM}

Para o levantamento dos dados foram escolhidos os alunos do $1^{\circ}$ período do curso de Arquitetura e Urbanismo da UFJF. Essa escolha é justificada por duas questões: a primeira, por serem estudantes de um curso que, atualmente, não faz mais parte da Faculdade de Engenharia, mas utiliza toda a infraestrutura desta e, segundo, por serem alunos recém-chegados à Universidade e, portanto, ainda encontram-se em estágio de adaptação, de modo que conseguem identificar as suas dificuldades e facilidades de orientação e de como perceberam o espaço na primeira semana de aulas.

Os dados foram coletados a partir da aplicação, aos estudantes, de um questionário composto por três partes, totalizando dezenove perguntas de caráter objetivo. A primeira parte consistiu em questões gerais como: idade, gênero, existência ou não de dificuldade visual ou motora. A segunda parte apresentou questões sobre a utilização da Faculdade de Engenharia na $8^{a}$ semana letiva, como: frequência de utilização dos equipamentos que compõe o campus, a forma de acesso à faculdade, dentre outras. A terceira e última parte 
abordou como se deu a utilização da Faculdade de Engenharia na primeira semana de aula, apontado os níveis de dificuldades e facilidades encontradas.

Por se tratar de questões psicométricas, foi utilizada a escala Likert para designar o nível de dificuldade de cada respondente em relação à localização de cada equipamento questionado. Para isso, as alternativas foram distribuídas da seguinte maneira: "muito difícil", "difícil", "nem fácil nem difícil", "fácil", "muito fácil", "desconheço sua localização". Abrangendo duas fases temporais distintas, o questionário proporcionou uma análise comparativa de acesso, circulação e utilização dos alunos no conjunto predial que compreende a Faculdade de Engenharia.

O questionário subsidiou a análise da influência do tempo na forma como os alunos se orientam e percebem o espaço no qual estão inseridos, além da análise da compreensão do espaço através do ambiente construído e a interferências de suas características na leitura do espaço pelo usuário.

\section{ANÁLISE DOS DADOS}

O questionário foi aplicado na turma de primeiro período no dia 24/05/2016, terçafeira, 7 semanas após o início do semestre letivo, e contemplou 09 questões referentes à semana da pesquisa e 05 questões referentes à primeira semana de aula. No dia da aplicação do questionário, os alunos se encontravam em aula em uma sala do Edifício Engenheiro Itamar Franco. Havia 36 alunos na faixa etária entre 17 e 22 anos, sendo que $58,3 \%$ tinham 18 anos completos no dia da aplicação.

No primeiro período, os alunos de arquitetura e urbanismo têm 9 disciplinas obrigatórias, totalizando 30 horas por semana. Dentro do grupo questionado, $50 \%$ respondeu que a frequência de utilização das instalações da Faculdade de Engenharia é entre 4 e 6 horas por dia e 38,88\%, entre 6 e 8 horas. O grupo analisado tem aulas no Edifício Engenheiro Itamar Franco 3 vezes por semana, todas as aulas nas salas de aula localizadas no terceiro andar. As outras disciplinas são ministradas no Galpão da Arquitetura, no Bloco A da Faculdade de Engenharia e no Instituto de Ciências Humanas, este último não pertencente ao recorte físico em estudo.

Dentre os acessos possíveis à Faculdade de Engenharia - anteriormente mencionados no item 3 -, o percentual de pessoas que acessaram o conjunto a pé ou utilizando ônibus urbano na primeira semana letiva foi $41,66 \%$. Em referência à semana da pesquisa, o mesmo número se manteve sobre o acesso utilizando ônibus urbano, enquanto que 0 acesso a pé teve uma queda de apenas $2,77 \%$. A Figura 06 demonstra a localização dos pontos de acesso e sua relação com as edificações onde são ministradas as aulas do grupo de amostragem utilizado.

Figura 04: Mapa de acessos à Faculdade de Engenharia - UFJF

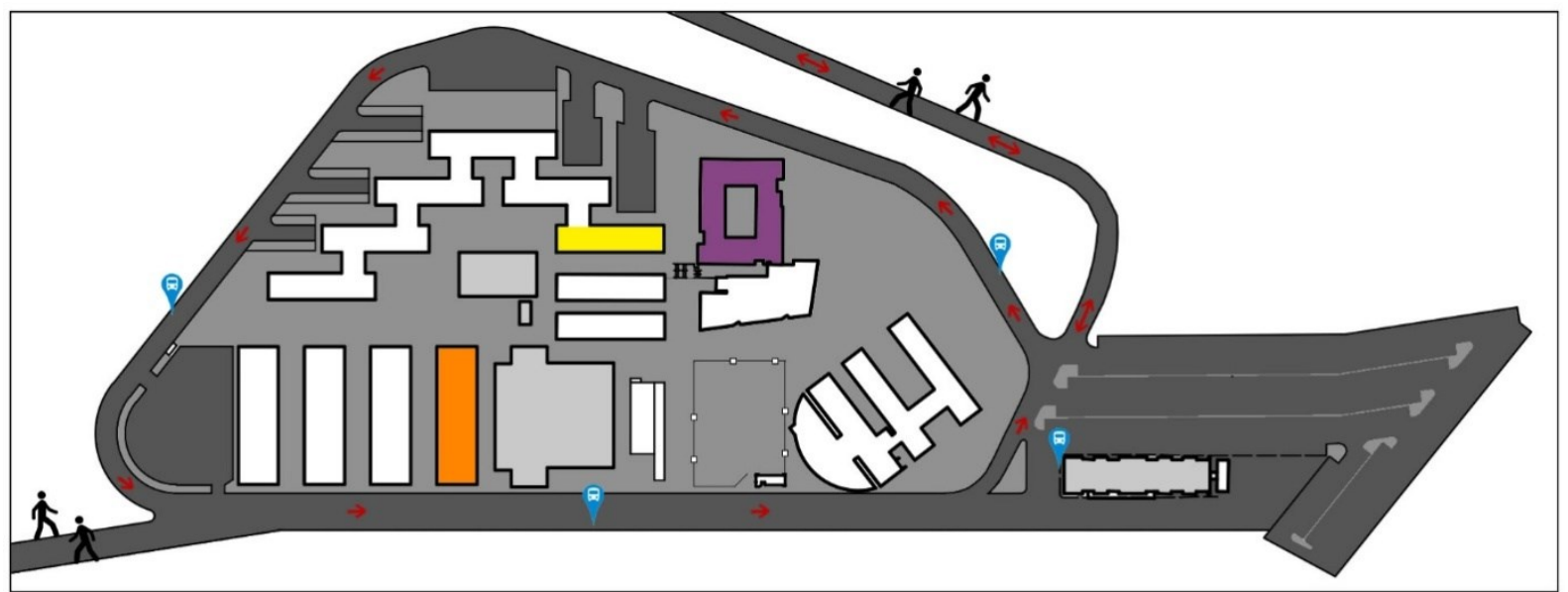

Ponto de ônibus urbano e circular

Galpão 4 - Galpão da Arquitetura Faculdade de Engenharia - Bloco A
Edifício Engenheiro Itamar Franco

$\uparrow$ Fluxo automóveis e ônibus

K Acesso à pé 
Fonte: Elaborado pelos autores.

A partir da análise do questionário constatou-se que $86,11 \%$ dos alunos não haviam tido contato com a Faculdade de Engenharia antes do início do período letivo. No entanto, um número maior - $88,88 \%$ - alegou não conhecer bem a área na primeira semana de aula. Sendo assim, $55,55 \%$ declararam que se orientaram muito dificilmente pelas instalações da faculdade e $36,11 \%$ apontaram que se orientaram dificilmente. Como justificativa para essa resposta, $83,33 \%$ declaram ter que dar muitas voltas para se localizar. Apenas $2 \%$ dos alunos disseram possuir algum tipo de dificuldade visual e nenhum deles declarou possuir dificuldades motoras.

Apesar do percentual de alta frequência de utilização da copiadora ter sido $72,22 \%$, $19,44 \%$ dizem ser difícil localizá-la. A figura 6 apresenta o gráfico que demonstra que as instalações que apontam maiores dificuldades de localização são as salas de aula, tanto na primeira semana, quanto 7 semanas depois, tendo como base as respostas "muito difícil" e "difícil" das questões sobre a avaliação do aluno acerca da dificuldade de localizar tais equipamentos.

Figura 05: Gráfico comparativo da dificuldade de localização de instalações da Faculdade de Engenharia nas $1^{\mathrm{a}}$ e $8^{\mathrm{a}}$ semana letiva.

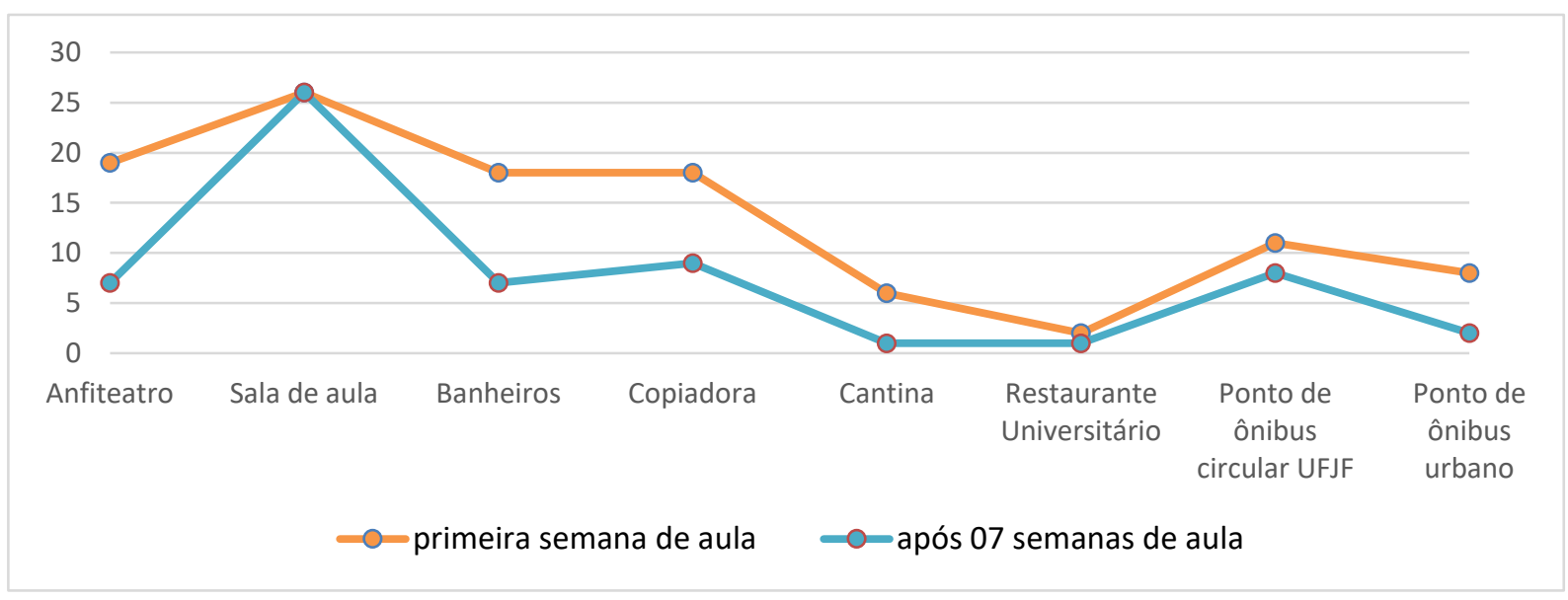

Fonte: Elaborado pelos autores.

A pesquisa indica, ainda, que a dificuldade de localização se dá majoritariamente $63,88 \%$ - pela falta de placas ou algum tipo de sinalização (figura 7 ), tanto na primeira semana, quanto na data da aplicação do questionário. A queda do percentual de alunos que justificaram a dificuldade de orientabilidade através da necessidade de dar muitas voltas em meio à Faculdade de Engenharia foi de 22,22\%.

Figura 06: Gráfico das razões apontadas pelos alunos em relação a dificuldade de orientabilidade dentro das dependências da Faculdade de Engenharia da UFJF na primeira semana de aula.

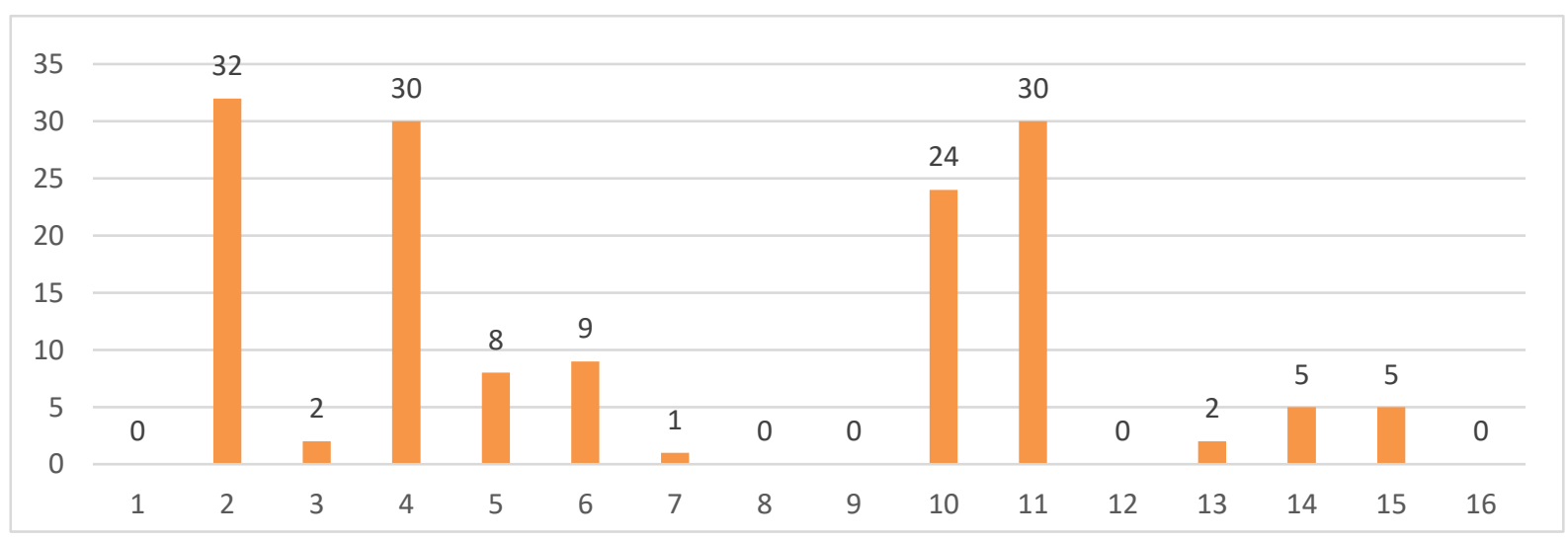


1. Já conheço bem a área; 2. Não conheço bem a área; 3. Uso características físicas dos prédios como pontos de referência; 4.Não consigo identificar características físicas dos prédios para usar como referência; 5 .Uso a numeração das salas como referência; 6 . Não é possível identificar a numeração das salas para usar como referência; 7. Presença de corredores mais largos; 8.Presença de corredores mais estreitos; 9.Existem placas de sinalização; 10.Não existem placas de sinalização;

11.Precisei dar muitas voltas; 12 .Não precisei dar muitas voltas; 13. Alto movimento de pessoas; 14.Baixo movimento de pessoas; 15.Informações de pessoas; 16.Outros

Fonte: Elaborado pelos autores.

Outro fator apontado pelo grupo foi a impossibilidade de identificar características físicas dos prédios para serem utilizados como referência para se orientarem espacialmente entre os edifícios componentes da FE. Dos 36 alunos que responderam a pesquisa, $83,33 \%$ revelaram não terem conseguido identificar características físicas como referência na primeira semana e após 7 semanas de aula, houve uma redução de $27,78 \%$. O alto percentual desse item é apoiado na constância das características arquitetônicas presentes nos edifícios em questão. As figuras 08 e 09 ilustram essa característica arquitetônica presente entre os Blocos A, B, C, D, E e F, construídos em meados da década de 1960.

Figuras 07: Faculdade de Engenharia / UFJF, três corredores distintos, do edifício projetado por Artur Arcuri na década de 1960. Figura 08a: corredor entre os blocos A e B. Figura 08b: corredor entre os blocos B e C. Figura 08c: corredor entre os blocos C e D.

Figura $7 a$

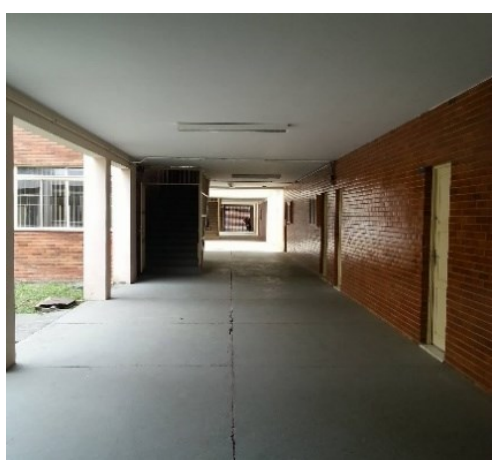

Figura $7 b$

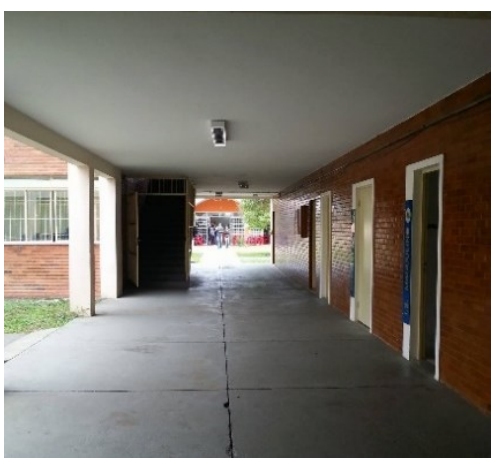

Figura 7c

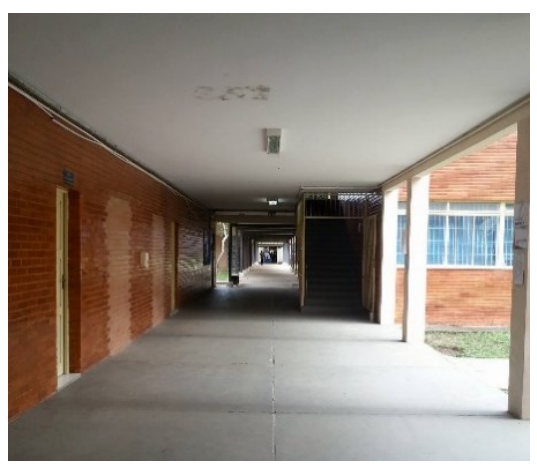

Fonte: Arquivo próprio, 2016

Já as figuras 09 e 10 ilustram a mesma característica que é, também, presente no Edifício Engenheiro Itamar Franco, de 2011. Em cada prédio, mesmo que distintos entre si, as características formais, materiais e de cores são repetidas internamente. $36,11 \%$ dos alunos indicaram que, consequentemente, utilizam a numeração das salas como referência para se orientarem, mesmo quando asseguram já conhecer bem a área.

Figura 08: Faculdade de Engenharia / UFJF, dois ângulos distintos do corredor do $3^{\circ}$ andar do Edifício Engenheiro Itamar Franco, onde se localizam salas de aula utilizadas três vezes por semana pelos alunos. 

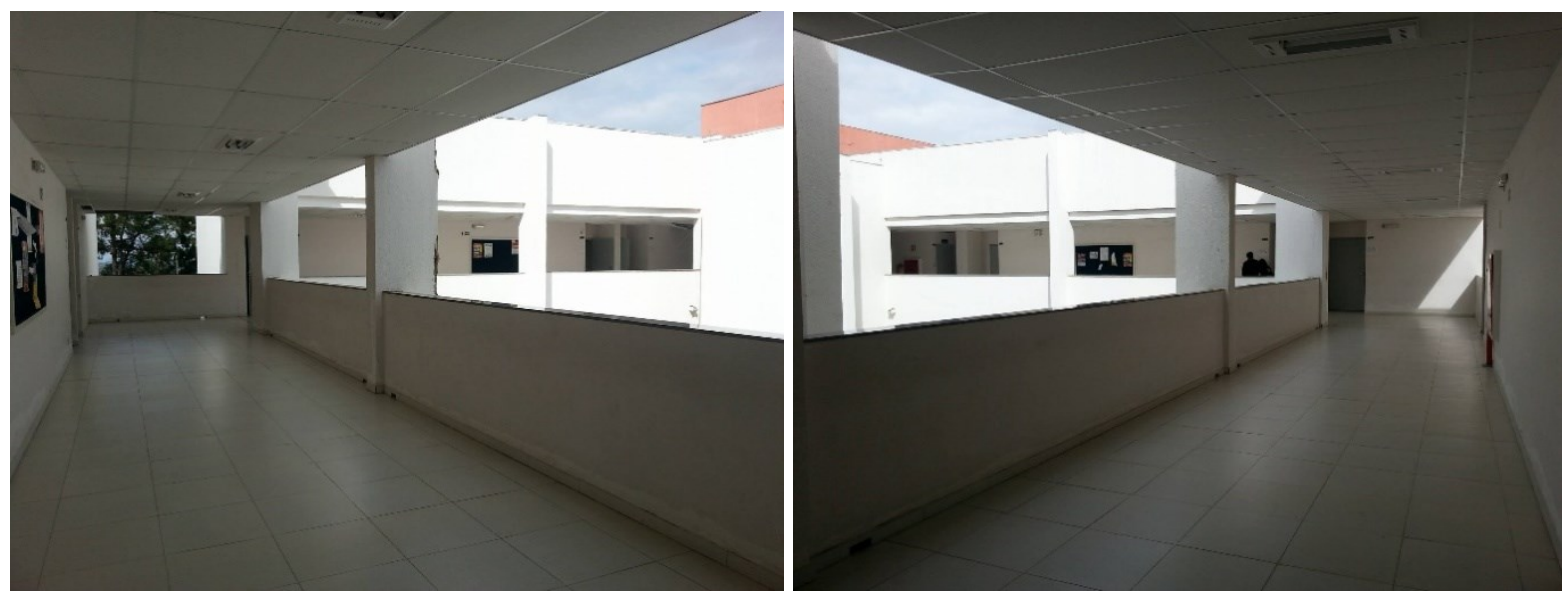

Fonte: Arquivo próprio, 2016

O percentual de $83,33 \%$ se repete em referência à necessidade de dar muitas voltas em meio às edificações para se orientarem no ambiente da Faculdade de Engenharia na primeira semana de aula. Quanto à mesma questão relacionada à oitava semana de aula, 0 percentual caiu $22,22 \%$. No entanto, $50 \%$ indicaram que ainda não conhecem bem a área da FE.

Cabe ressaltar que não foram identificadas diferenças significativas em um comparativo entre gêneros. Por exemplo, $61,53 \%$ dos estudantes que se identificaram com o gênero feminino apontaram que precisaram dar muitas voltas na primeira semana de aula para se localizar no Campus, assim como, $60 \%$ dos estudantes que se identificaram com o gênero masculino.

\section{CONSIDERAÇÕES FINAIS}

A revisão de literatura sobre ergonomia cognitiva, percepção e orientabilidade contribuiu para a delimitação do problema de investigação, bem como para o conhecimento de outras pesquisas relacionadas ao tema pesquisado, contribuindo para revelar experiências de outros grupos semelhantes. Dentro das publicações encontradas, nenhuma abordou a percepção de alunos de arquitetura dentro do ambiente universitário, o que enfatiza o caráter inédito deste estudo sobre a percepção e orientabilidade dos mesmos. A revisão dos conceitos permitiu ainda a elaboração mais cautelosa do questionário a ser aplicado, com abordagem mais consistente e objetiva nas questões.

Com a aplicação do questionário foi possível perceber quais são as principais dificuldades dos alunos ao se locomoverem na Faculdade de Engenharia e na Faculdade de Arquitetura e Urbanismo da UFJF. O questionário favoreceu a compreensão da diversidade de percepções e a análise da evolução da percepção e orientação dos alunos na primeira semana de aula e sete semanas após o início da mesma.

Foram identificados os pontos negativos em relação à estrutura dos prédios, que dificultam a orientabilidade do usuário e com base nas respostas obtidas, conclui-se que os prédios não possuem uma sinalização adequada para facilitar a chegada do usuário ao seu destino final, implicando assim em inconvenientes, como dar muitas voltas para chegar a seu destino, além da dificuldade de identificar características físicas que possam ser utilizadas como pontos de referência. A falta de características exclusivas unifica cada prédio, porém dificulta a orientação e percepção espacial. Com a construção e ampliação de novos prédios na Faculdade de Engenharia da UFJF, é possível observar que não houve um planejamento de sinalização e orientação, o que complementa a dificuldade de percepção e orientação do usuário entre os prédios.

Alguns campi universitários brasileiros possuem em seus próprios sites, manuais de sinalização, visando à melhoria e padronização da informação no ambiente construído. A 
Faculdade de Engenharia da UFJF não possui um manual que regulamenta a sinalização, nem diretrizes específicas que indiquem uma padronização no sistema de orientação do espaço, o que acarreta em grandes dificuldades de orientação para ao usuário.

Este estudo fornece dados que podem servir como base para pesquisas futuras, além de apontar pontos a serem melhorados no ambiente, acarretando a melhoria da qualidade do espaço construído da Faculdade de Engenharia da UFJF. Considera-se importante a recomendação de estudos similares que caracterizem um arcabouço mais consolidado de informações sobre o tema.

\section{REFERÊNCIAS}

ABBAD, Gardênia da Silva; BORGES-ANDRADE, Jairo Eduardo. Aprendizagem humana em organizações de trabalho. In: ZANELLI, J. C.; BORGES-ANDRADE, J. E.; BASTOS, A. V. B. (Orgs.). Psicologia, organizações e trabalho no Brasil. Porto Alegre: Artmed, 2004. p. $237-275$.

ABERGO (Associação Brasileira de Ergonomia). O que é ergonomia. Disponível em: <http://www.abergo.org.br/internas.php?pg=o_que_e_ergonomia > Acesso em: 15 jun. 2016.

BINS ELY, V. H. M. Ergonomia + Arquitetura: buscando um melhor desempenho do ambiente físico. Anais do $3^{\circ}$ Ergodesign. Rio de Janeiro: LEUI/PUC-Rio, 2003.

BINS ELY, V. H. Estudo de legibilidade e orientabilidade no centro urbano de Florianópolis. Anais do $4^{\circ}$ Ergodesign: Rio de Janeiro: LEUI/PUC-Rio, 2004.

BINS ELY, V.H.M. Orientar-se no Espaço: Condição Indispensável para a Acessibilidade. In: Seminário Nacional Acessibilidade no Cotidiano. Rio de Janeiro: UFRJ, 2004.

CARPMAN, J.R. About Wayfinding. Disponível em:

< http://www.wayfinding.com/wayfinding/about-wayfinding/.> Acesso em: 15 jun. 2016.

FERNANDES, S.R, PELISSARI, V.B, SOUZA, V.J. Uso da percepção ambiental como instrumento de gestão educacional e ambiental. In: $23^{\circ}$ Congresso Brasileiro de Engenharia Ambiental e Sanitária. Cariacica, 2005.

LAVILLE, Antoine. Ergonomia. São Paulo: EPU, Ed. Da Universidade de São Paulo, 1977.

OKAMOTO, J. Percepção Ambiental e Comportamento. São Paulo: Editora Makenzie, 2002.

OLENDER, MARCOS. Projeto "História da UFJF". 2012, disponível em <http://projetohistoria-da-ufjf.webnode.com/>.Acesso em 03 mai.2016.

MENESES, Renata de Almeida, CAVALCANTE, Brenno, DEMAISON, André Leonardo. Sinalização de um Campus Universitário em São Luís, MA: Uma abordagem a partir da ergonomia informacional. In: $13^{\circ}$ Congresso Internacional de Ergonomia e Usabilidade de Interfaces Humana-Tecnologia: Produto, Informações, Ambiente Construído e Transportes. Juiz de Fora, 2013.

RIBEIRO, Lúcia Gomes; MONT'ALVÃO, Cláudia (Org.). Ergonomia no ambiente construído: teoria e prática. In: MORAES, Anamaria. Ergodesign do Ambiente Construído e 
habitado: Ambiente Urbano, Ambiente Público, Ambiente Laboral. Rio de Janeiro: iUsEr, 2004. p. 146.

GRADUAÇÃO EM ARQUITETURA E URBANISMO, disponível em: <http://www.ufjf.br/arquitetura/graduacao/curso/infraestrutura/> Acesso em: 21 jun. 2016.

UNIVERSIDADE FEDERAL DE JUIZ DE FORA. Disponível em: $<$ http://www.ufjf.br/secom/2013/08/15/uma-das-fundadoras-da-ufjf-faculdade-de-engenhariacompleta-99-anos/> Acesso em: 19 de jun.2016.

. Disponível em: <http://www.ufjf.br/iad/instituto-de-artes-e-design-iad/historico/>

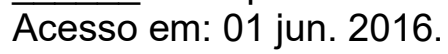

Disponível em: <http://www.ufjf.br/secom/2009/03/03/funcionamento-dorestaurante-universitario-ru/> Acesso em 01 jun. 2016.

Disponível em: <http://www.ufjf.br/engenharia/cursos/>Acesso em 27 jun. 2016. 